Case Report

\title{
Lupus-Associated Pulmonary Arterial Hypertension: Variable Course and Importance of Prompt Recognition
}

\author{
Kofi A. Mensah, ${ }^{1}$ Rajwardhan Yadav, ${ }^{1}$ Terence K. Trow, ${ }^{2}$ \\ Cristina M. Brunet, ${ }^{1}$ and Wassim H. Fares ${ }^{2}$ \\ ${ }^{1}$ Section of Rheumatology, Department of Internal Medicine, Yale University School of Medicine, 333 Cedar Street, \\ New Haven, CT 06510, USA \\ ${ }^{2}$ Section of Pulmonary, Critical Care and Sleep Medicine, Department of Internal Medicine, Yale University School of Medicine, \\ 333 Cedar Street, New Haven, CT 06510, USA
}

Correspondence should be addressed to Kofi A. Mensah; kofi.mensah@yale.edu

Received 12 April 2015; Revised 21 June 2015; Accepted 23 June 2015

Academic Editor: Ting Fan Leung

Copyright (C) 2015 Kofi A. Mensah et al. This is an open access article distributed under the Creative Commons Attribution License, which permits unrestricted use, distribution, and reproduction in any medium, provided the original work is properly cited.

We describe a critically ill young woman with systemic lupus erythematosus (SLE) presenting with circulatory shock, multiorgan dysfunction, and elevated right-sided heart pressures. She was found to have recurrent acute severe pulmonary arterial hypertension (PAH) in the setting of an SLE flare. Our report highlights the variable course that SLE-associated PAH can take in the same patient and the implications of this for instituting the most effective treatment approach with each episode. This report also highlights the potential for SLE-associated PAH to present with life-threatening symptoms requiring critical care level interventions. We also describe evidence-based therapies, which can result in significant improvement in symptoms, function, and long-term outcomes.

\section{Introduction}

Pulmonary arterial hypertension $(\mathrm{PAH})$ is a potentially lethal manifestation of systemic lupus erythematosus (SLE). Pulmonary hypertension $(\mathrm{PH})$ is defined as an elevated mean pulmonary arterial pressure (mPAP) of $25 \mathrm{mmHg}$ or greater at rest, and it is a heterogeneous condition with multiple underlying etiologies. The World Health Organization (WHO) has classified PH into five categories (Table 1) [1]. In total, the prevalence in the general population of these five classes of $\mathrm{PH}$ is unknown but has been estimated recently to be up to $10-20 \%$, depending on the method of diagnosis and the population studied, with WHO group 2 (related to left heart failure) being the most common $[1,2]$. The clinical severity of $\mathrm{PH}$ can be graded according to the WHO functional class system (Table 1).

\section{Case Report}

A 25-year-old woman with SLE presented in the spring of 2014 with hypotension and hypoxemia. She was in her usual state of health until two weeks prior to presentation, when she noticed worsening generalized body aches, malaise, excessive daytime sleepiness, and progressive shortness of breath with exertion. She described open sores in her mouth, productive cough, palpitations, chest pain, abdominal pain, lower extremity swelling, and diffuse joint pain. She denied fevers or chills. She took prednisone $60 \mathrm{mg}$ daily at the onset of her symptoms.

Her past medical history was significant for SLE diagnosed in 2011, when she developed arthralgia, rash, and Raynaud's phenomenon. She had a positive anti-nuclear antibody (ANA) and proteinuria, and renal biopsy showed WHO V glomerulonephritis. She was initially treated with cyclophosphamide and then maintained on $200 \mathrm{mg}$ hydroxychloroquine twice daily and $60 \mathrm{mg}$ oral prednisone daily. She had been hospitalized in 2012 with an SLE flare and severe WHO group 1 SLE-associated PAH, which presented in a manner similar to the 2014 presentation described in this case report. She was treated with pulse methylprednisolone and intravenous cyclophosphamide in 2012 without specific pulmonary vasodilator therapy, gradually recovered, and was 
TABLE 1: World Health Organization (WHO) classification schemes for pulmonary hypertension (PH) and functional class (FC). The examples given for each WHO PH group are not comprehensive but offer representations of disease processes in each category. The patient in this report is group $1 \mathrm{PH}$ with FC IV.

\begin{tabular}{|c|c|}
\hline Category & Characteristics \\
\hline $\begin{array}{l}\text { All groups of } \\
\mathrm{PH}\end{array}$ & $\begin{array}{l}\mathrm{mPAP} \text { of } \geq 25 \mathrm{mmHg} \text { at rest, } \\
\text { PVR of }>240 \text { Dynes-sec } / \mathrm{cm}^{5}, \\
\text { PAWP } \leq 15 \mathrm{mmHg} \\
\text { (except for group } 2 \mathrm{PH} \text { where } \\
\text { PAWP } \geq 15 \mathrm{mmHg} \text { ). }\end{array}$ \\
\hline Group $1 \mathrm{PH}$ & $\begin{array}{l}\text { Pulmonary arterial hypertension (PAH). It } \\
\text { includes idiopathic PAH, PAH from genetic } \\
\text { mutations, medications, HIV, portal } \\
\text { hypertension, congenital heart disease, and } \\
\text { schistosomiasis. It also includes PAH } \\
\text { associated with connective tissue diseases such } \\
\text { as SLE and systemic sclerosis. }\end{array}$ \\
\hline Group $2 \mathrm{PH}$ & $\begin{array}{l}\text { Pulmonary venous hypertension (left-sided } \\
\text { heart disease/failure). }\end{array}$ \\
\hline Group $3 \mathrm{PH}$ & $\begin{array}{l}\text { PH owing to chronic lung diseases and/or } \\
\text { hypoxemia (e.g., chronic obstructive } \\
\text { pulmonary disease, sleep disordered breathing, } \\
\text { and interstitial lung diseases). }\end{array}$ \\
\hline Group $4 \mathrm{PH}$ & PH from chronic thromboembolic disease. \\
\hline Group $5 \mathrm{PH}$ & $\begin{array}{l}\text { PH occurring in several miscellaneous } \\
\text { conditions whose association with PH is poorly } \\
\text { understood (e.g., sarcoidosis, } \\
\text { lymphangioleiomyomatosis, and Langerhans } \\
\text { cell histiocytosis). }\end{array}$ \\
\hline FC I & No symptoms with ordinary physical activity. \\
\hline FC II & $\begin{array}{l}\text { Fatigue, dyspnea, chest pain, or syncope with } \\
\text { ordinary physical activity. }\end{array}$ \\
\hline FC III & $\begin{array}{l}\text { Symptoms that develop with less than ordinary } \\
\text { physical activity. }\end{array}$ \\
\hline FC IV & $\begin{array}{l}\text { Symptoms with any physical activity, or while } \\
\text { at rest. }\end{array}$ \\
\hline
\end{tabular}

discharged home on prednisone $60 \mathrm{mg}$ daily and hydroxychloroquine $200 \mathrm{mg}$ twice daily. She was nonadherent to her medications and clinic visits.

On physical exam at the 2014 admission, she was afebrile, hypoxemic with an oxygen saturation of $89 \%$ on room air, and hypotensive with a BP of $73 / 52 \mathrm{mmHg}$. She had shallow, nonbleeding, ulcerated hard palate lesions. Pulmonary auscultation revealed decreased breath sounds and tachypnea. She had distended neck veins, regular tachycardia (135 beats/minute), and a prominent second pulmonic heart sound. Her abdomen was tender to palpation. There was no synovitis or joint effusion. Her fingers and toes were cold and clammy with a purplish hue and skin mottling. She had no focal neurological deficits.

A computerized tomographic angiogram of the chest was negative for pulmonary embolus and lung parenchymal disease. A V/Q scan was low probability for pulmonary embolus without moderate or large segmental mismatched perfusion defects. ECG showed a new right bundle branch block. Chest $\mathrm{X}$-ray revealed cardiomegaly. Transthoracic echocardiogram

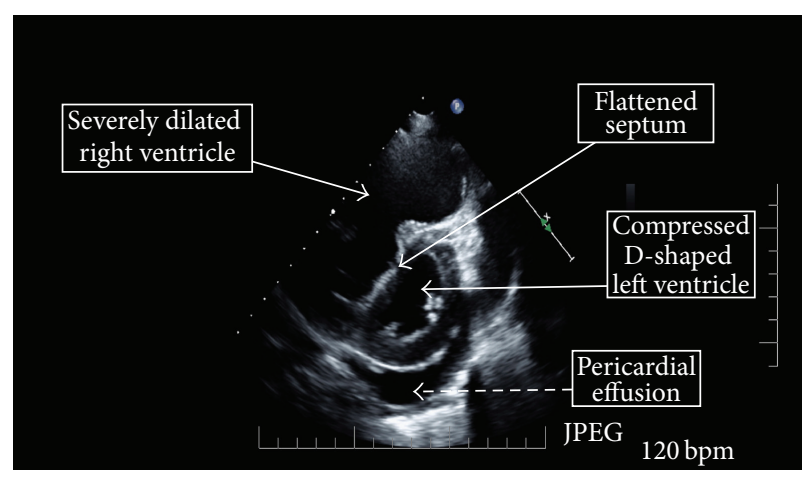

(a)

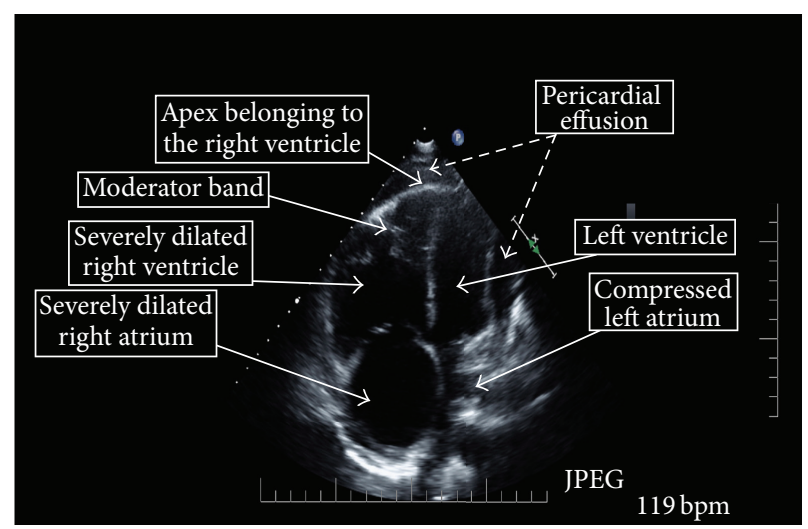

(b)

FIGURE 1: Echocardiogram of the patient demonstrating key features of severe pulmonary arterial hypertension. (a) Left parasternal short axis view. (b) Four-chamber apical view. Elevated pulmonary artery systolic pressures lead to a dilated right ventricle and right atrium. Dilation of the right ventricle causes flattening of the interventricular septum and the normally larger left ventricle becomes constricted. The rapid heart rate of $120 \mathrm{bpm}$ also reduces the time for left ventricular filling and coronary artery perfusion. All of this results in hemodynamic compromise with decreased cardiac output, which can result in cardiogenic shock.

(TTE) showed a moderate to large pericardial effusion without tamponade, severe right atrial enlargement and tricuspid regurgitation, a plethoric inferior vena cava with decreased respiratory variation consistent with increased right atrial pressure, severe right ventricular (RV) enlargement, with severe RV systolic dysfunction, and RV wall hypokinesis. The RV systolic pressure (RVSP) was estimated at $70 \mathrm{mmHg}$. The left ventricle cavity size was decreased with interventricular septal flattening in systole and diastole consistent with RV pressure and volume overload (Figure 1).

The patient was admitted to the medical intensive care unit for management. Laboratory analysis revealed evidence of tissue hypoperfusion with severe anion-gap metabolic acidosis ( $\mathrm{pH}$ 7.17, anion gap of $21 \mathrm{mmol} / \mathrm{L}$, and serum bicarbonate of $8 \mathrm{mmol} / \mathrm{L}$ ), central venous oxygen saturation of $49 \%$, and multiorgan failure manifested by a creatinine $83.9 \mu \mathrm{mol} / \mathrm{L}$ (up from $38.1 \mu \mathrm{mol} / \mathrm{L}$ at baseline), AST/ALT 3350/1150 U/L (normal range 0-34), and INR 2.2 (in the absence of anticoagulant therapy). Her inflammatory and 
TABLE 2: Laboratory assessment of immunologic and inflammatory disease activity at admission and at follow-up 8 weeks later showing serologic phenotype and response to therapy.

\begin{tabular}{|c|c|c|c|}
\hline $\begin{array}{l}\text { Immunologic } \\
\text { parameter (units, } \\
\text { where applicable) }\end{array}$ & $\begin{array}{l}\text { Reference } \\
\text { range }\end{array}$ & $\begin{array}{l}\text { Admission } \\
\text { value }\end{array}$ & $\begin{array}{l}\text { Postdischarge } \\
\text { follow-up value }\end{array}$ \\
\hline $\mathrm{ESR}(\mathrm{mm} / \mathrm{hr})$ & $0-20$ & 35 & 46 \\
\hline CRP (mg/L) & $0.1-3.0$ & 27.9 & 9.2 \\
\hline C3 (mg/dL) & $88-145$ & 33 & 128 \\
\hline $\mathrm{C} 4(\mathrm{mg} / \mathrm{dL})$ & $16-39$ & $<10$ & 22 \\
\hline ANA titer & $<1: 40$ & $>1: 10,240^{\wedge}$ & $1: 2,560$ \\
\hline $\begin{array}{l}\text { Anti-dsDNA Ab* } \\
(\mathrm{IU} / \mathrm{mL})\end{array}$ & $<12.5$ & 25.7 & $<12.5$ \\
\hline $\begin{array}{l}\text { Anti-centromere } \\
\mathrm{Ab}\end{array}$ & $<1: 40$ & $<1: 40$ & \\
\hline Anti-SCL70 & Negative & Negative & \\
\hline Anti-La Ab & Negative & Negative & \\
\hline Anti-Ro Ab & Negative & Positive & \\
\hline Anti-Smith $\mathrm{Ab}^{*}$ & Negative & Positive & \\
\hline Anti-RNP $\mathrm{Ab}^{* *}$ & Negative & Positive & \\
\hline $\begin{array}{l}\text { Anti-cardiolipin } \\
\mathrm{Ab}^{* *}(\mathrm{CU})\end{array}$ & $<20$ & 10.6 & \\
\hline $\begin{array}{l}\text { Beta-2 } \\
\text { glycoprotein (CU) }\end{array}$ & $<20$ & 14.9 & \\
\hline
\end{tabular}

${ }^{\wedge}$ Speckled pattern. ${ }^{*}$ Patients positive for anti-dsDNA and anti-Smith had better response to immunosuppressive therapy during an SLE-associated PAH flare [10]. ${ }^{* *}$ Anti-RNP and anti-cardiolipin positivity correlates with evidence of $\mathrm{PH}$ on echocardiogram [11]. Ab: antibody; ESR: erythrocyte sedimentation rate; CRP: C-reactive protein; ANA: antinuclear antibody; dsDNA: double-stranded DNA; RNP: ribonucleoprotein.

autoimmune markers confirmed an SLE flare with hypocomplementemia and elevation in anti-dsDNA titer (Table 2). Extensive infectious work-up, including blood cultures, was negative. Given the constellation of these clinical findings (and the absence of an infection, acute loss of circulating blood volume, or central nervous system insult), she was diagnosed with acute cardiogenic shock and started on vasopressors and inotropes.

More than a week into her hospitalization, her SLE flare was improving but definitely not resolved as she continued to be hemodynamically unstable requiring vasopressors and inotropes (though at lower dosages). Thus, right heart catheterization (RHC) was performed at that time (while still on inotropes and vasopressors) to guide further PAHand RV-directed therapies. The RHC showed markedly worse hemodynamic parameters compared to values from 2012, when a RHC was done after she received immunosuppressive therapy for a similar presentation (Table 3). Given these clinical and hemodynamic findings she was diagnosed as WHO group $1 \mathrm{PAH}$, which is associated with connective tissue diseases such as systemic sclerosis and SLE. The severity of her clinical presentation placed her in WHO functional class IV, which is characterized by symptoms with any physical activity or while at rest (Table 1).
TABLE 3: Hemodynamic parameters from right heart catheterization of the patient after successful treatment of 2012 episode of PAH compared to the current presentation of severe $\mathrm{PAH}$ and cardiogenic shock.

\begin{tabular}{|c|c|c|c|}
\hline $\begin{array}{l}\text { Hemodynamic } \\
\text { parameter } \\
\text { (units) }\end{array}$ & $\begin{array}{l}\text { Reference } \\
\text { range }\end{array}$ & $\begin{array}{c}\text { Symptom-free } \\
\text { baseline } \\
(2012, \\
\text { posttreatment })\end{array}$ & $\begin{array}{l}\text { Current PAH } \\
\text { exacerbation }\end{array}$ \\
\hline RAP (mmHg) & $1-6$ & 1 & 7 \\
\hline PAWP (mmHg) & $6-15$ & 4 & 4 \\
\hline PAP (mmHg) & $20-30 / 10-15$ & $27 / 11$ & $86 / 51$ \\
\hline $\begin{array}{l}\text { Mean PAP } \\
(\mathrm{mmHg})\end{array}$ & $10-20$ & 17 & 62 \\
\hline $\mathrm{CO}(\mathrm{L} / \mathrm{min})$ & $4-8$ & 7.8 & 4.2 \\
\hline $\mathrm{CI}\left(\mathrm{L} / \mathrm{min} / \mathrm{m}^{2}\right)$ & $2.6-4.2$ & 4.9 & 2.6 \\
\hline $\begin{array}{l}\text { PVR (Dynes- } \\
\mathrm{sec} / \mathrm{cm}^{5} \text { ) }\end{array}$ & $\leq 240$ & 128 & 784 \\
\hline
\end{tabular}

RAP: right atrial pressure; PAWP: pulmonary artery wedge pressure; PAP: pulmonary artery pressure designated here as systolic/diastolic; $\mathrm{CO}$ : cardiac output; CI: cardiac index; PVR: pulmonary vascular resistance. ${ }^{*}$ Note: measurements made while patient was on vasopressors and inotropes for clinical and echocardiographic evidence of acute cardiogenic shock given the need for emergent hemodynamic support and stabilization before the RHC could be performed safely.

\section{Discussion}

The prevalence of PAH in patients with SLE is unclear with several studies suggesting a range from 0.5 to $43 \%$, though 0.5 to $17.5 \%$ is reported in more recent studies [1, $3,4]$. The variation in reported prevalence may be related to the methods used to diagnose $\mathrm{PAH}$, specifically the use of echocardiography versus the gold standard of RHC [4]. Echocardiography provides a noninvasive screening method, but the accuracy of echocardiography is about $50 \%$ in estimating RVSP [5]. As a screening method, echocardiography has a sensitivity of $50-90 \%$ and a specificity of $75-96 \%$ when compared to RHC in patients with connective tissue disease $[6,7]$. Thus, while it is a useful screening method, it is important to note that the margin of error in accuracy and the range of sensitivities present in echocardiographic estimation of RVSP in the relatively small population of individuals affected by SLE-associated PAH can considerably impact the ability to determine the true prevalence of this condition.

Molecular mechanisms contributing to the pathophysiology of PAH involve fibroblast and endothelial cell dysfunction that results in impaired production of vasodilators (including nitric oxide (NO) and prostacyclin) and overexpression of vasoconstrictors such as endothelin. These molecular derangements affect vascular tone and promote pathological vascular remodeling leading to pulmonary arterial vasoconstriction, in situ thrombosis, and occasionally complex plexiform lesions [8]. As the disease progresses, vascular remodeling and fibrosis eventually cause RV dilation and failure $[1,9]$. In PAH patients with SLE, macrophages, lymphocytes, antinuclear antibodies, and complement have been identified histologically in the pulmonary vasculature [10]. 
In some SLE patients, there is overactivation of transcription factors known to be pathophysiologically relevant in idiopathic PAH such as hypoxia inducible factor-1 alpha (HIF-1a). There are also increased anti-endothelial cell antibodies, which lead to increased release of endothelin $[4,11]$. Other relevant autoantibodies are anti-cardiolipin and antiRNP antibodies, which have a positive correlation with the diagnosis of $\mathrm{PH}$ by echocardiography [11]. Despite these associations, it is unclear whether the presence of these autoantibodies has a direct mechanistic influence on the pathogenesis of PAH.

At the tissue level, vasculitis and thrombosis seen in SLE may contribute directly to vascular remodeling and damage. Furthermore, pulmonary venous hypertension from left ventricular dysfunction, hypoxic vasoconstriction from chronic hypoxemic lung disease, thromboses related to antiphospholipid antibody syndrome, and venoocclusive processes related to the hypercoagulable state in SLE may contribute indirectly to the development of $\mathrm{PH}$ [4].

Treatment options for PAH target three main molecular vascular derangements pathways [12]. The NO pathway is targeted by PDE-5 inhibitors and guanylate cyclase stimulators (sGC). The endothelin-1 pathway is targeted by endothelinreceptor antagonists (ERAs), and the prostacyclin pathway is targeted by synthetic prostacyclins and prostacyclin analogues, called "prostanoids." PDE-5 inhibitors work by preventing PDE-5 from impairing the cyclic-GMP mediated vasodilatory function of NO. Guanylate cyclase stimulators increase cyclic-GMP (the downstream molecule of NO) and may function even in the absence of NO. ERAs inhibit endothelin, which is a potent vasoconstrictor overexpressed in PAH. Prostanoids work via a cyclic-AMP mediated relaxation of vascular smooth muscle causing vasodilation [12]. These four classes of drugs, though currently approved for treatment of $\mathrm{PAH}$, are not approved for therapy in WHO groups 2-5 $\mathrm{PH}$ where these medications may cause harm in some cases (except for sGC which is also approved in $\mathrm{WHO}$ group $4 \mathrm{PH})$.

$\mathrm{PAH}$ is associated with other connective tissue diseases, such as systemic sclerosis and mixed connective tissue disease, and therapy aimed specifically at PAH may be sufficient in those cases. In contrast, patients with SLE and PAH often have worsening of PAH during SLE flares. In these patients presenting with active SLE and evidence of RV failure, induction immunosuppression followed by maintenance regimens significantly improved hemodynamic parameters [10]. In these studies, immunosuppressive therapy with monthly IV pulses of $600 \mathrm{mg} / \mathrm{m}^{2}$ of cyclophosphamide for six months plus prednisone $0.5-1 \mathrm{mg} / \mathrm{kg} /$ day for four weeks with a slow taper led to significant reduction in mPAP, improvement in cardiac index, and reduction in PVR [10].

In subgroup analyses, responders to this immunosuppressive approach were more likely to be anti-dsDNA and anti-Smith antibody positive and also had higher disease activity at the time of treatment. For those SLE patients with worse functional classification, a combination of the immunosuppressive strategy with cyclophosphamide and prednisone plus $\mathrm{PAH}$-specific therapy with a prostanoid, ERA, or PDE-5 inhibitor resulted in improved hemodynamic outcomes compared to immunosuppressive therapy alone [10]. The importance of the benefit of combined SLE- and PAH-directed therapy is underscored by the finding that 3 year survival from time of diagnosis in patients with SLErelated $\mathrm{PAH}$ is $74 \%$ and is significantly better than the 3year survival for patients with the more prevalent systemic sclerosis-associated PAH (47\%) [13].

According to the Registry to Evaluate Early and LongTerm Pulmonary Arterial Hypertension Disease Management (REVEAL) risk score, this patient had a one-year mortality rate of $15-30 \%$ based on having WHO functional class IV, PAH associated with connective tissue disease, and a pericardial effusion [14]. In accordance with recent guidelines, a parenteral prostanoid can be used for treatment in this case [15]. She agreed to start a continuous infusion of treprostinil with informed consent after a patient-centered discussion of the importance of adherence as well as the risks, benefits, and alternatives (including ERAs which would have required her to get monthly documented pregnancy testing).

She was also given 1 gram of methylprednisolone daily for three days, and IV cyclophosphamide $500 \mathrm{mg} / \mathrm{m}^{2}$ to treat the acute SLE exacerbation, which had likely precipitated the worsening of her PAH. Hydroxychloroquine was restarted at $200 \mathrm{mg}$ BID as was a gradual steroid taper. A similar regimen of immunosuppression in 2012, when she presented with SLE flare manifested by cutaneous vasculitis and PAH, resulted in complete recovery from acute right heart failure, without the need for pulmonary vasodilator therapy. At that time, she presented earlier in the course of a PAH exacerbation and thus had a better WHO functional class. Previous studies demonstrate that an immunosuppressive regimen alone without specific pulmonary vasodilators may be sufficient for SLE patients with less severe (better functional class) $\mathrm{PAH}$ exacerbations [10].

The combination of immunosuppressive therapy and PAH-specific therapy resulted in rapid improvements in her hemodynamic and respiratory status. The dosage of treprostinil was titrated to efficacy; she gradually was weaned off supplemental oxygen and inotropic support. She was discharged home after a 5-week hospitalization. Discharge medications included prednisone $1.5 \mathrm{mg} / \mathrm{kg} / \mathrm{day}$, hydroxychloroquine $200 \mathrm{mg}$ BID, sildenafil $80 \mathrm{mg}$ TID, and treprostinil by subcutaneous infusion at $49 \mathrm{ng} / \mathrm{kg} / \mathrm{min}$.

When seen in follow-up, her renal and hepatic failure had completely resolved. Her treprostinil infusion rate was increased to achieve further improvement in RV function. Laboratory studies also showed normalization of complements and a decrease in the anti-dsDNA level (Table 2). She was transitioned to prednisone $40 \mathrm{mg}$ daily and continued on hydroxychloroquine $200 \mathrm{mg}$ BID.

Despite the initial recovery from a life-threatening SLErelated PAH exacerbation, and multiple efforts to educate the patient about her life-threatening disease and the high mortality associated with abrupt discontinuation of prostanoid infusion, her subsequent clinical course was complicated by missed follow-up appointments and by nonadherence to her therapies, including infused prostanoid therapy. Five months after her presentation, she was brought to the ER in cardiopulmonary arrest and was unable to be resuscitated. 
An important take-away message of this case report is the prompt recognition of severe $\mathrm{PAH}$ as a cause for progressive exertional dyspnea and hemodynamic instability in patients with rheumatologic diseases such as SLE. TTE provides a noninvasive bedside screening technique. Also important is the variable course that SLE-associated PAH can take in the same patient and the implications for instituting the most effective treatment approach with each episode.

There are effective, evidence-based therapeutic options for treating both PAH itself with vasodilator therapy (e.g., a prostanoid, ERA, or PDE-5 inhibitor) and the SLE flares leading to PAH exacerbation with immunomodulators (e.g., high-dose corticosteroids and cyclophosphamide). The cause of PAH in SLE is often a result of concomitant molecular and tissue-level factors (autoimmune disease activity, endothelial damage, and thrombosis). Given the difficulty in ascribing the etiology of an exacerbation to any one factor, treatment strategies employing both immunomodulators and pulmonary vasodilators to target the multiple convergent pathophysiologic pathways are likely more beneficial than therapy with a single pharmacologic modality. More trials are needed to delineate the relative role of immunosuppressive therapy in SLE-associated PAH compared with pulmonary vasodilator therapy, especially as recent survival data shows that pulmonary vasodilator therapy is pivotal in SLE-associated PAH.

A multidisciplinary approach involving pulmonologists and/or cardiologists with experience in $\mathrm{PH}$ and rheumatologists with an understanding of the complex management of PAH in SLE and other connective tissue diseases is important to therapeutic success. Equally important is a collaborative partnership with the patient in carrying out the treatment plan. As demonstrated by the literature reviewed herein, early recognition of the symptoms of PAH in SLE allows for prompt and effective intervention that may favorably impact the patient's functional status and survival.

\section{Conflict of Interests}

The authors declare that there is no conflict of interests regarding the publication of this paper.

\section{References}

[1] S. J. Shah, "Pulmonary hypertension," The Journal of the American Medical Association, vol. 308, no. 13, pp. 1366-1374, 2012.

[2] G. Strange, D. Playford, S. Stewart et al., "Pulmonary hypertension: prevalence and mortality in the Armadale echocardiography cohort," Heart, vol. 98, no. 24, pp. 1805-1811, 2012.

[3] A. Prabu, K. Patel, C.-S. Yee et al., "Prevalence and risk factors for pulmonary arterial hypertension in patients with lupus," Rheumatology, vol. 48, no. 12, pp. 1506-1511, 2009.

[4] A. Dhala, "Pulmonary arterial hypertension in systemic lupus erythematosus: current status and future direction," Clinical and Developmental Immunology, vol. 2012, Article ID 854941, 12 pages, 2012.

[5] M. R. Fisher, P. R. Forfia, E. Chamera et al., "Accuracy of doppler echocardiography in the hemodynamic assessment of pulmonary hypertension," The American Journal of Respiratory and Critical Care Medicine, vol. 179, no. 7, pp. 615-621, 2009.
[6] C. P. Denton, J. B. Cailes, G. D. Phillips, A. U. Wells, C. M. Black, and R. M. D. U. Bois, "Comparison of Doppler echocardiography and right heart catheterization to assess pulmonary hypertension in systemic sclerosis," British Journal of Rheumatology, vol. 36, no. 2, pp. 239-243, 1997.

[7] V. M. Hsu, A. E. Moreyra, A. C. Wilson et al., "Assessment of pulmonary arterial hypertension in patients with systemic sclerosis: comparison of noninvasive tests with results of rightheart catheterization," Journal of Rheumatology, vol. 35, no. 3, pp. 458-465, 2008.

[8] R. M. Tuder, S. L. Archer, P. Dorfmüller et al., "Relevant issues in the pathology and pathobiology of pulmonary hypertension," Journal of the American College of Cardiology, vol. 62, supplement 25, pp. D4-D12, 2013.

[9] M. Humbert, N. W. Morrell, S. L. Archer et al., "Cellular and molecular pathobiology of pulmonary arterial hypertension," Journal of the American College of Cardiology, vol. 43, no. 12, supplement, pp. 13S-24S, 2004.

[10] X. Jais, D. Launay, A. Yaici et al., "Immunosuppressive therapy in lupus- and mixed connective tissue disease-associated pulmonary arterial hypertension: a retrospective analysis of twenty-three cases," Arthritis and Rheumatism, vol. 58, no. 2, pp. 521-531, 2008.

[11] Y. K. Xia, S. H. Tu, Y. H. Hu et al., "Pulmonary hypertension in systemic lupus erythematosus: a systematic review and analysis of 642 cases in Chinese population," Rheumatology International, vol. 33, no. 5, pp. 1211-1217, 2013.

[12] W. H. Fares and T. K. Trow, "Targeted approaches to the treatment of pulmonary hypertension," Therapeutic Advances in Respiratory Disease, vol. 6, no. 3, pp. 147-159, 2012.

[13] R. Condliffe, D. G. Kiely, A. J. Peacock et al., "Connective tissue disease-associated pulmonary arterial hypertension in the modern treatment era," American Journal of Respiratory and Critical Care Medicine, vol. 179, no. 2, pp. 151-157, 2009.

[14] R. L. Benza, D. P. Miller, M. Gomberg-Maitland et al., "Predicting survival in pulmonary arterial hypertension: insights from the registry to evaluate early and long-term pulmonary arterial hypertension disease management (REVEAL)," Circulation, vol. 122, no. 2, pp. 164-172, 2010.

[15] D. B. Taichman, J. Ornelas, L. Chung et al., "Pharmacologic therapy for pulmonary arterial hypertension in adults: CHEST guideline and expert panel report," Chest, vol. 146, no. 2, pp. 449-475, 2014. 


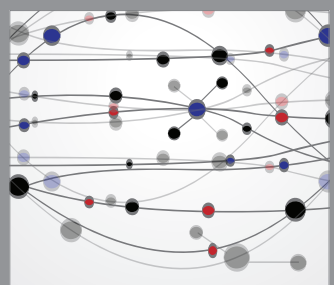

The Scientific World Journal
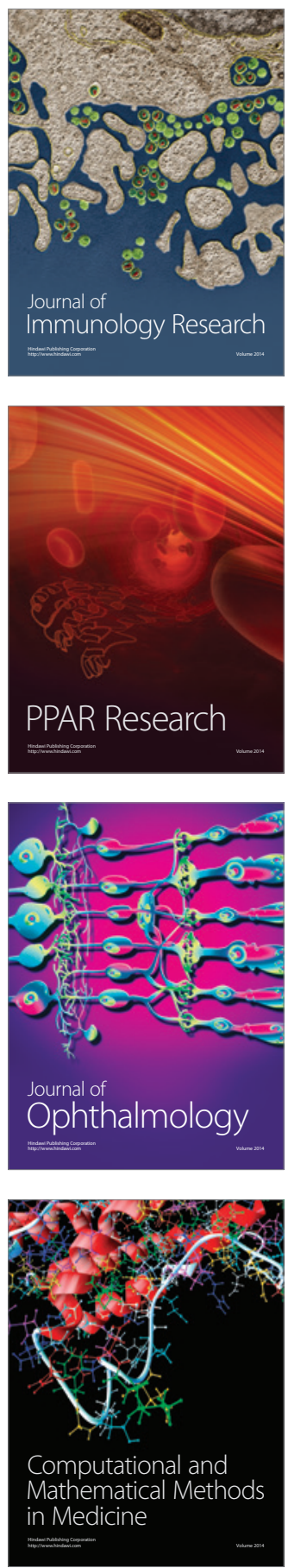

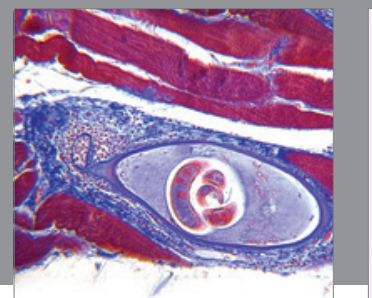

Gastroenterology

Research and Practice
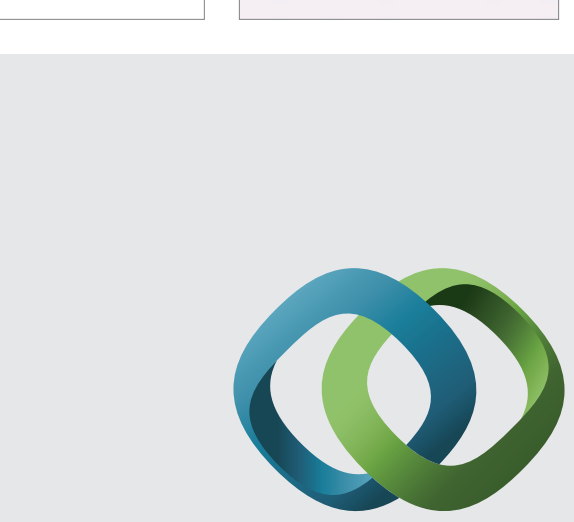

\section{Hindawi}

Submit your manuscripts at

http://www.hindawi.com
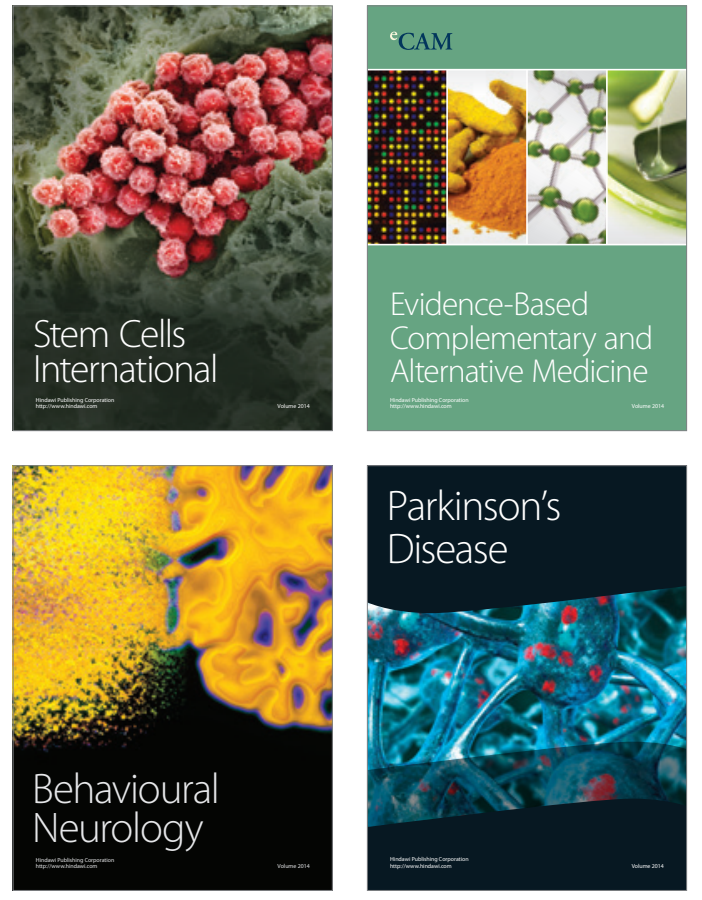
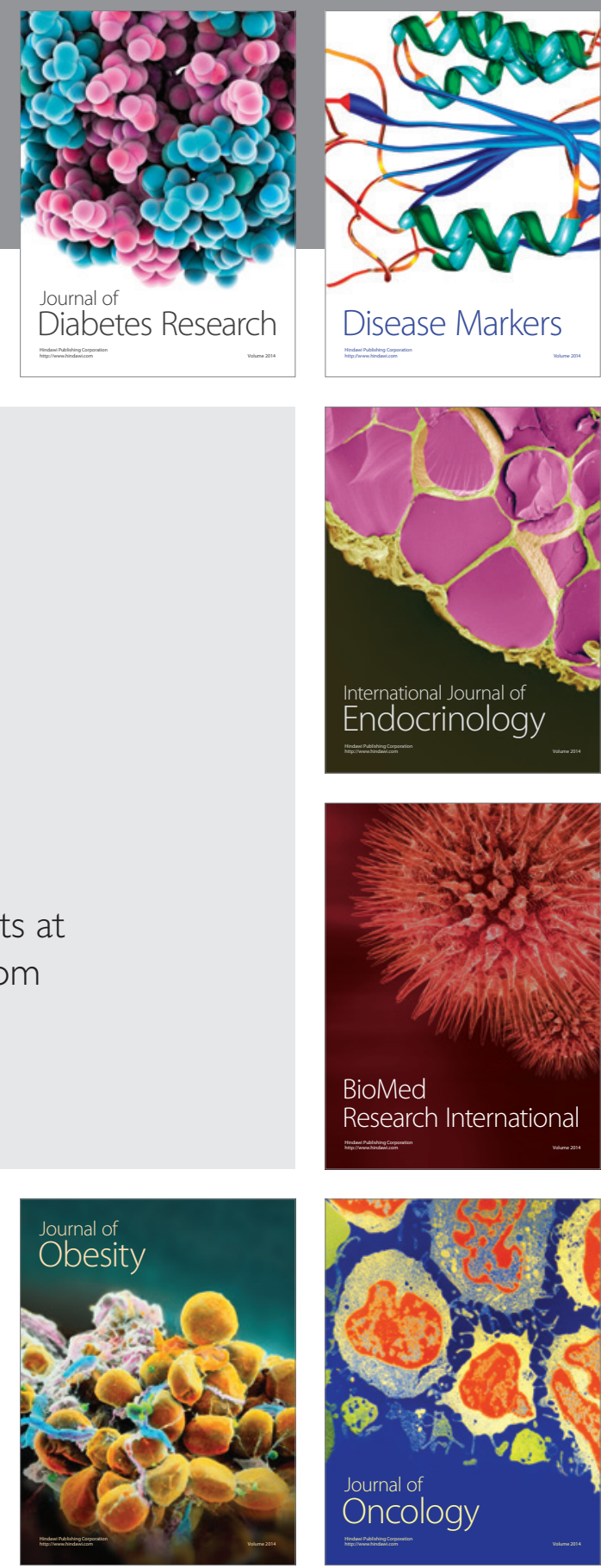

Disease Markers
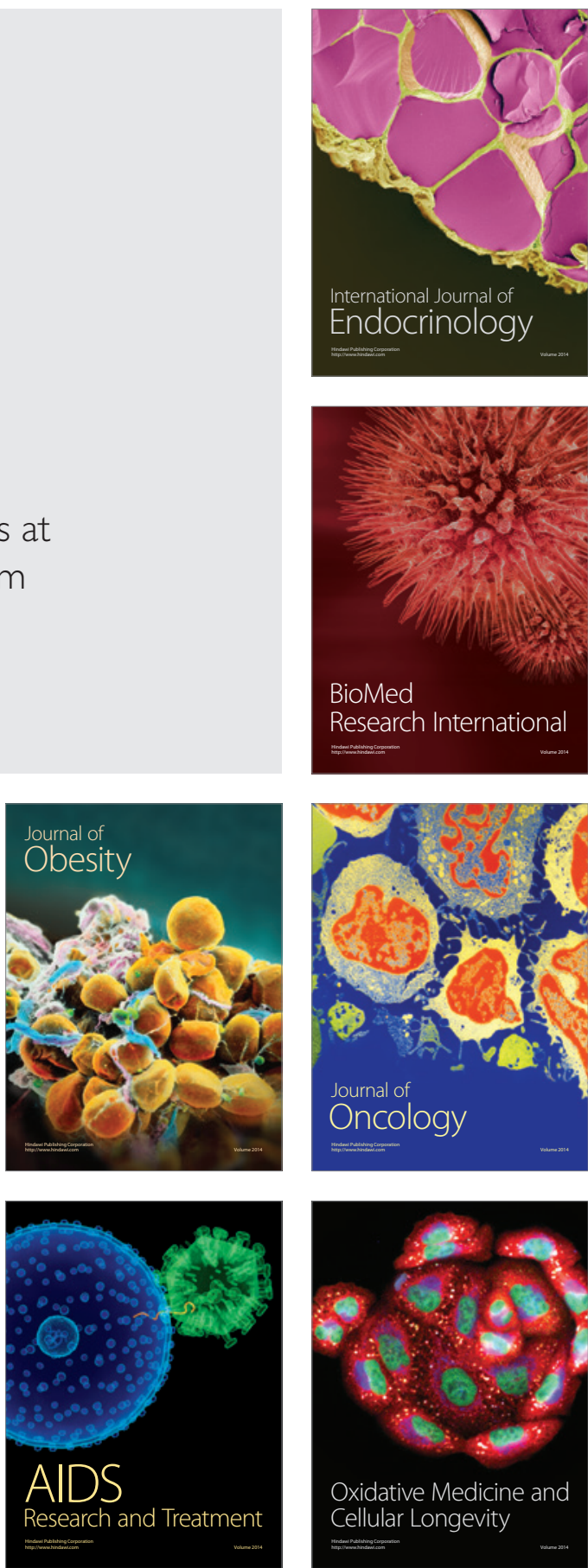